\title{
Green Synthesis and Antimicrobial Potential of Silver/ Gold Nanoparticles Functionalized with Debregeasia salicifolia D. Don
}

\author{
Sami Bawazeer ${ }^{1}$, Abdur Rauf, Khaliq Ur Rahman², Jawad Ali², Ghias Uddin ${ }^{3}$, \\ Fatima Begum ${ }^{3}$, Mohammad S. Mubarak ${ }^{4}$ and Mohamed Fawzy Ramadan ${ }^{5,6 *}$ (i) \\ ${ }^{1}$ Pharmacognosy Department, College of Pharmacy, Umm Al-Qura University, Makkah, Saudia Arabia. \\ ${ }^{2}$ Department of Chemistry, University of Swabi, Anbar-23561, Khyber Pakhtunkhwa, Pakistan. \\ ${ }^{3}$ Institute of Chemical Sciences, University of Peshawar, K.P.K Peshawar - 25120, Pakistan. \\ ${ }^{4}$ Department of Chemistry, The University of Jordan, Amman, 11942, Jordan. \\ ${ }^{5}$ Deanship of Scientific Research, Umm Al-Qura University, Makkah, P.O.Box 715, Saudi Arabia. \\ ${ }^{6}$ Agricultural Biochemistry Department, Faculty of Agriculture, Zagazig University, Zagazig - 44519, Egypt.
}

\begin{abstract}
The aim of the current study was to detect various secondary metabolites in the extract of Debregeasia salicifolia, and to synthesize stable silver/gold nanoparticles (Ag/AuNPs) from D. salicifolia methanol crude extract. The antioxidant, antibacterial, and antifungal activities of the methanol crude extract, various isolated fractions, and the synthesized nanoparticles were evaluated. Phytochemical analyses of the methanol extract/fractions indicated the presence of tannins, saponins, flavonoids, steroids, terpenoids, coumarins, emodins, and soluble starch. Gold and silver nanoparticles have been subsequently synthesized from the methanol crude extract by green synthesis, and characterized by UV and IR spectroscopic techniques. Size of the particles was determined with the aid of an atomic force microscope (AFM). The results revealed that the size of AuNPs was 5-100 nm, and that of AgNPs was in the range 5-100 $\mathrm{nm}$. Bioactivity screening revealed that chloroform and $n$-hexane fractions exhibited significant 2,2-diphenyl-1-picrylhydrazyl (DPPH·) radical scavenging potential against quercetin. Additionally, the extract/fractions and AuNPs were also subjected to antimicrobial activity screening against a number of strains of microbes. Among extracts, $\boldsymbol{n}$-hexane fraction showed good antifungal activity as compared to other fractions, whereas in the case of anti-bacterial activity, extract and fractions were active against Gram positive and Gram negative bacterial strain. AuNPs were exhibited moderate activity against all tested bacterial strains.
\end{abstract}

Keywords: Green synthesis, Atomic force microscope, antiradical, antioxidant, antimicrobial

*Correspondence: mhassanien@uqu.edu.sa

(Received: September 27, 2020; accepted: November 03, 2020)

Citation: Bawazeer S, Rauf A, Ur Rahman K, et al. Green Synthesis and Antimicrobial Potential of Silver/Gold Nanoparticles Functionalized with Debregeasia salicifolia D. Don. J Pure Appl Microbiol. 2020;14(4):2513-2523. doi: 10.22207/JPAM.14.4.28

(C) The Author(s) 2020. Open Access. This article is distributed under the terms of the Creative Commons Attribution 4.0 International License which permits unrestricted use, sharing, distribution, and reproduction in any medium, provided you give appropriate credit to the original author(s) and the source, provide a link to the Creative Commons license, and indicate if changes were made. 


\section{INTRODUCTION}

Nanotechnology play important rule in several applications including cosmetics, biomedical device, electronics, food, energy for refining the enterprise and presentation. Therefore green nanotechnology, designed nonmaterial in the field of electronics, communication, energy and medicine sector ${ }^{1}$. Nanotechnology has wide application in field of herbal drug discovery, development of nanoherbal product having low toxicity and high bioavailability. For the synthesis of gold $(\mathrm{Au})$ and silver $(\mathrm{Ag})$ nanoparticles $(\mathrm{Ag} /$ AuNPs) various plants were utilized such as Emblica officinalis, Aloe vera, Camellia sinensis, Brassica juncea, Memecylon edule, Cinnamommum camphora, Mentha piperita, Diopyros kaki, and Azadirachta indica ${ }^{1,2}$. Functionalized Ag/AuNPs with precise optical and geometrical properties have attracted considerable attention owing to their potential use as drug delivery vehicles which found several medicinal applications. Ag/AuNPs displayed numerous biological traits and uses including biosensors, genomics, cancer treatment through laser phototherapy, delivery of drug to a target area, and DNA optical bio-imaging.

AuNPs have wide application due to unique tunable surface plasmon resonance in biomedical science, Immunochromatographic identification of pathogens in clinical specimens, photo thermal therapy, drug delivery and cancer imaging $^{1,2}$. A more comprehensive review dealing with AuNPs and their applications in biology and medicine has been published by Dykman and $\mathrm{Khlebtsov}^{3}$. Due to their antibacterial properties, silver compounds have found applications in medical fields. In this context, AgNPs exhibited outstanding physical, chemical, and biological properties. AgNPs with sizes below $100 \mathrm{~nm}$ are widely used in medical devices. In addition, AgNPs have been employed in numerous fabrics and as coatings on certain implants 4 .

Debregeasia salicifolia belongs to the family Urticaceae, which thrives in India, Pakistan, Afghanistan, and tropical Africa ${ }^{5}$. D. salicifolia is an evergreen tree, up to $5 \mathrm{~m}$ tall, with fibrous bark scabrous, young shoots, and $2.5 \mathrm{~cm}$ long leaves. In Pakistan, this genus is only characterized by the species $D$. salicifolia, which is a small tree that grows in the northern areas of Pakistan ${ }^{6}$. The compound $3 \beta, 19 \alpha$-dihydroxy-30-norurs-12-ene, a triterpenoid, has been isolated from the methanol extract of $D$. salicifolia stem ${ }^{7}$. Several compounds have been isolated from this plant including ursolic acid, pomolic acid, pololic acid methyl ester, tormentic acid and 3-(trans-cinnamoyloxy)-19 -hydroxy-urs-12-ene ${ }^{8}$. Moreover, the methanol extract of $D$. salicifolia displayed antimicrobial activities against various bacterial strains ${ }^{9}$.

Free radicals might cause a large number of diseases including cancer, neural disorders, Alzheimer's disease, aging, and cardiovascular diseases, among others. Protection against these harmful free radicals can be improved by sufficient intake of antioxidants ${ }^{10}$. Antioxidants play a central role in the fight against a number of human diseases as free radical scavengers. In this respect, reactive oxygen species (ROS), are chemically reactive oxygen-containing molecules which play a very important role in the host defence mechanism against micro-organisms ${ }^{11,12}$. However, amplified production of ROS may result in a number of diseases and cause inflammation.

The aim of this work was to identify secondary metabolites in the extracts of $D$. salicifolia, and to synthesize stable silver/gold nanoparticles (Ag/AuNPs) from D. salicifolia methanol crude extract. The antioxidant, antibacterial, and antifungal activities of the methanol crude extract, various isolated fractions, and the synthesized nanoparticles were evaluated.

\section{EXPERIMENTAL Materials}

D. salicifolia was collected from Dist. Dir Lower KPK, Pakistan. Dr. Barkathullah, a botanist at the Department of Botany, University of Peshawar (Pakistan), identified and authenticated the plant. A voucher specimen (2417(PUP) UOP) was deposited at the herbarium located at the Department of Botany, University of Peshawar (Pakistan).

\section{Extraction}

The dried plant material was powdered by means of local grinder machine. Powdered plant material (200 gm) was soaked in methanol for a period of one week to obtain polar crude extract. The methanol crude extract was subjected to different organic solvent to obtain various fractions including $n$-hexane, chloroform, and ethyl acetate. The crude methanol extract and its 
isolated fractions was assessed for phytochemical and biological studies.

\section{Phytochemical analysis}

Phytochemical screening tests were performed on the crude methanol extract and its various fractions to identify active phytochemicals responsible for the biological properties of $D$. salicifolia, and for the synthesis of nanoparticles. These tests were performed according to published procedures $^{13-19}$. For detection of alkaloids, $0.2 \mathrm{~g}$ of each crude extract and various fractions were warmed with $2 \% \mathrm{H}_{2} \mathrm{SO}_{4}$ for 5 min in a water bath to afford solutions which contain plant particles. Each solution was filtered using Whatman filter paper No 1 and a few drops of Dragendroff's reagent were added to each clear filtrate; the appearance of a red precipitate indicates the presence of alkaloids. Presence of tannins was confirmed by mixing $0.3 \mathrm{~g}$ of each extract or fraction in distilled water, heating in a water bath for few mins, then filtering using the help of Whatman filter paper No1. Few drops of $\mathrm{FeCl}_{3}$ were added to each filtrate; the appearance of a dark green solution confirms the presence of tannins. The presence of an anthraquinone was confirmed by mixing $0.3 \mathrm{~g}$ extract/fractions with $10 \% \mathrm{HCl}$ followed by heating for few mins in a water bath. Solutions were filtered and allowed to cool, followed by addition of an equal volume of $\mathrm{CHCl}_{3}$ to each filtrate. Few drops of $10 \% \mathrm{NH}_{3}$ were added to each filtrate with heating in a water bath, wherein the formation of a rose-pink colour establishes the presence of anthraquinones. Similar procedures were used to identify glycosides, saponins, flavonoids, sphlobatanins, steroids, terpenoids, cardiac glycosides, coumarins, emodins, carbohydrates, anthocyanin and betacyanins, reducing sugars, and starch.

\section{Synthesis of Au/AgNPs}

Au/AgNPs were synthesized according to the standard procedure ${ }^{20-22}$. The plant methanol crude extract $(0.5 \mathrm{~g})$ was dissolved in $100 \mathrm{~mL}$ of triple distilled water to make stock solutions which were stored at $4^{\circ} \mathrm{C}$ for further use. A $1 \mathrm{mM}$ solution of silver salt was prepared by dissolving $17 \mathrm{mg}$ of $\mathrm{AgNO}_{3}$ in $100 \mathrm{~mL}$ of deionized water to prepare a salt solution. Similarly, a $1 \mathrm{mM}$ solution of a gold salt was prepared by dissolving $34 \mathrm{mg}$ of $\mathrm{H}\left[\mathrm{AuCl}_{4}\right]$ in deionized water to make a $100 \mathrm{~mL}$ solution. Both salt solutions were placed at $4^{\circ} \mathrm{C}$ in brownish reagent bottles coated with aluminium foil. For the bio-reduction of $\mathrm{Au}^{+3}$ to $\mathrm{Au}^{0}$, a freshly prepared plant extract $(5 \mathrm{~mL})$ was added, dropwise with a syringe to different ratios of $10^{-3} \mathrm{M}$ $\mathrm{H}\left[\mathrm{AuCl}_{4}\right]$ solution. Change in color indicates the formation of Au/AgNPs.

\section{Antioxidant assay}

The free radical scavenging ability and the antioxidant activity of the crude extracts and the newly synthesized Au/AgNPs was determined according to Duan and coworkers ${ }^{23,24}$. Sample solutions of various concentrations ranging from 10 to $100 \mu \mathrm{g} / \mathrm{mL}$ of extracts or Au/AgNPs were mixed with 1,1-diphenyl-2-picrylhydrazyl (DPPH.) solution (in methanol). DPPH - is a fairly stable violet-colored free radical that is frequently employed in the determination of free radical scavenging activity. The mixture was placed in the dark for $30 \mathrm{~min}$ and the absorbance was measured at $517 \mathrm{~nm}$. A decrease in absorbance of DPPH. solution implies a rise in the free radical scavenging activity. Antiradical activity (\%) was calculated by using the following formula:

$\% \mathrm{DPPH} \cdot=100\left(\mathrm{~A}_{\text {control }}-\mathrm{A}_{\text {sample }}\right) / \mathrm{A}_{\text {control }}$

Where $A_{\text {control }}$ is the absorbance of control (the absorbance of the blank), and $A_{\text {sample }}$ is the absorbance of tested samples.

\section{Antibacterial activity}

Plant crude extracts (different separated sub-fractions) and Au/AgNPs were screened for their antibacterial activity against the Gramnegative bacterial strains including; $K$. pneumonia and Gram-positive S. aureus, S. epidermidis, and $B$. sibtilis. The strains were obtained from stock culture in the PNRL laboratory (Institute of Chemicals Sciences, University of Peshawar, KPK, Pakistan). The organisms were kept at $4^{\circ} \mathrm{C}$ in a Muller-Hinton agar (MHA). Modified agarwell diffusion method was employed to examine the antibacterial activity of plant crude extracts, their sub-fractions, and Au/AgNPs. Cultures were cultivated at $37^{\circ} \mathrm{C}$ for $24-72 \mathrm{~h}$ in triplicate. A Petridish was used for broth culture; $0.6 \mathrm{~mL}$ of that broth culture was added, and Petri-dishes were sterilized followed by addition of $20 \mathrm{~mL}$ of sterilized molten MHA to each petri-dish. Wells were bored in the medium and $0.2 \mathrm{~mL}$ of plant crude extracts and separated sub-fractions were added to each well by means of a micropipette, whereas $2 \mathrm{mg} /$ $\mathrm{mL}$ of Au/AgNPs was used. Streptomycin (2 mg/ 
$\mathrm{mL}$ ) was used as a standard drug. Petri-dishes were kept in laminar flow hood for $1 \mathrm{~h}$ for proper diffusion, and plates were incubated at $37^{\circ} \mathrm{C}$ for $24 \mathrm{~h}$. On the very next day, the zone of inhibition was measured ${ }^{16}$.

\section{Antifungal activity}

The antifungal efficacy of plants crude extracts, various sub-fractions, and NPs against the fungal strains ( $A$. flavus, $A$. niger, and $A$. solani) was tested following published procedures ${ }^{25}$. The fungal strains were obtained from stock culture in the PNRL laboratory, (Institute of Chemicals Sciences, University of Peshawar, KPK, Pakistan). The agar tube dilution method was employed in this investigation. In this method, $24 \mathrm{mg} / \mathrm{mL}$ each of crude extract and sub-fraction was mixed with sterile dimethyl sulfoxide (DMSO) and shaken until proper dissolution to make stock solutions. Four $\mathrm{mL}$ of sabouraud dextrose agar (SDA) was distributed in a cap tube shape screw and autoclaved for 15 min at $120^{\circ} \mathrm{C}$ then slowly cooled to $15^{\circ} \mathrm{C}$. A Stock solution $(66.6 \mu \mathrm{L})$ and non-solidified SDA media were combined to give a final concentration of 400 $\mu \mathrm{g}$ of the extract per $\mathrm{mL}$ of SDA. The tubes were placed in a slanted location at room temperature $\left(25^{\circ} \mathrm{C}\right)$ for solidification of media. For non-mycelial growth, each tube was inoculated with a piece (diameter $4 \mathrm{~mm}$ ) on inoculums from a seven-dayold culture of fungi. In all of these experiments, an agar surface streak was subjected, whereas DMSO was used as a control. Fungal inhibition growth was measured after 7 days of incubation at $28 \pm 1^{\circ} \mathrm{C}$ and relative humidity of approximately $40-50 \%$; results were expressed as percentage antifungal activity.

\section{Phytotoxic assay}

Plant crude extracts, various fractions, and $\mathrm{Ag} / \mathrm{Au}$ nanoparticles were examined for their phytotoxicity against Lamna minor L. For this purpose, various fractions of crude extracts and NPs in three different concentrations (10, 100 and $1000 \mathrm{mg} / \mathrm{mL}$ ) were employed. Sterilized flasks were inoculated with stock solutions of the aforementioned concentrations. Ten plants (Lamna minor) were added to each flask having three rosettes of fronds along with $20 \mathrm{~mL}$ of medium and were kept at $28^{\circ} \mathrm{C}$ for 7 days, and their growth was observed. On the $7^{\text {th }}$ day, the growth of fronds in each flask was analyzed in comparison with a negative control. A number of fronds in each flask was counted, recorded, and results were analyzed. Results were obtained according to the following published formula ${ }^{18}$ :

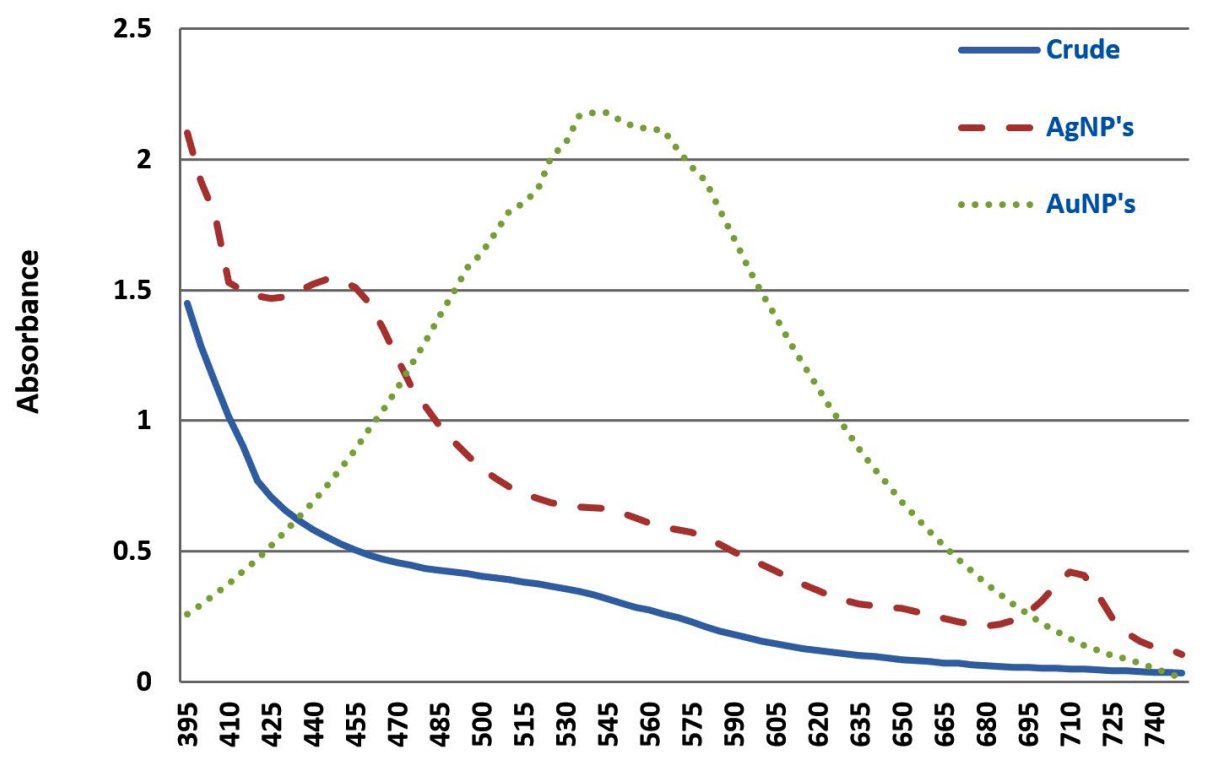

Wave Length $(\mathrm{nm})$

Fig. 1. UV-Visible analysis of $D$. salicifolia crude extract, gold nanoparticles (AuNPs) and silver nanoparticles (AgNPs). 
Growth regulation $=(100-\mathrm{T} / \mathrm{N}) \times 100$

Where $T=$ number of fronds in the test sample and $\mathrm{N}=$ number of fronds in the control Cytotoxicity assay

For a preliminary assessment of cytotoxicity of the plant crude extracts, isolated fractions, and nanoparticles, the brine shrimp method was used ${ }^{18}$. Briefly, different concentration $(10,100$, and $1000 \mu \mathrm{g} / \mathrm{mL})$ of plant crude extracts, isolated fractions, and nanoparticles were prepared. Brine shrimps nauplii were hatched in a precise tank at room temperature. Prepared solutions $(10,100$, and $1000 \mu \mathrm{g} / \mathrm{mL})$ were applied to 09 vials, 3 for each concentration. Ten nauplii shrimps along with $5 \mathrm{~mL}$ of brine solution were introduced into each vial. Dry yeast suspension was also introduced into each vial as their food and the incubation was achieved for $24 \mathrm{~h}$ under illumination, and a number of alive shrimps in each vial was counted by means of a magnifying glass then the percent death rate was calculated for each concentration. Data were processed with the aid of Graph Pad Prism version 6. Results and $\mathrm{LD}_{50}$ values were expressed as the mean of three replicates.

\section{Spectral analysis}

UV-Visible spectral analysis

Optical properties of Ag/AuNPs were determined with the aid of a UV-Vis spectrophotometer. UV-spectra of the plant extracts and Ag/AuNPs, in the range $395-750 \mathrm{~nm}$, were recorded at different times with different ratios $^{19}$. Nanoparticles with the most promising spectra were taken for further characterization and biological activities. In a similar fashion, spectra of stock solutions were also recorded when the color changed due to the addition of metallic salts, and these spectra were compared for the confirmation of the formation of nanoparticles.

\section{FT-IR spectral analysis}

An FT-IR instrument (IR Prestige-21, Shimadzu $400-4000 \mathrm{~cm}^{-1}$ ) was used to examine the chemical composition of the plant crude extracts and the synthesized $\mathrm{Ag} / \mathrm{AuNPs}$. Both plants crude extracts and synthesized nanoparticles in dried powdered form were analyzed, as potassium bromide $(\mathrm{KBr})$ pellets, in the range from 400 to $4000 \mathrm{~cm}^{-1}$. Spectra were then compared to confirm the formation of nanoparticles ${ }^{19,24-28}$.

\section{Atomic force microscopy (AFM) imagining}

AFM technique was used for the characterization of $\mathrm{Ag} / \mathrm{AuNPs}$ from $D$. salicifolia methanol crude extract. The size and shape of $\mathrm{Ag} /$ AuNPs were analyzed by using AFM (Multimode, nanoscopellla, veeco, CA, USA, in tapping method. For the AFM analysis of Ag/AuNPs, sample were prepared by dissolving think films in double distilled water and then dispersed on freshly cleaved sheet of mica ${ }^{29}$.

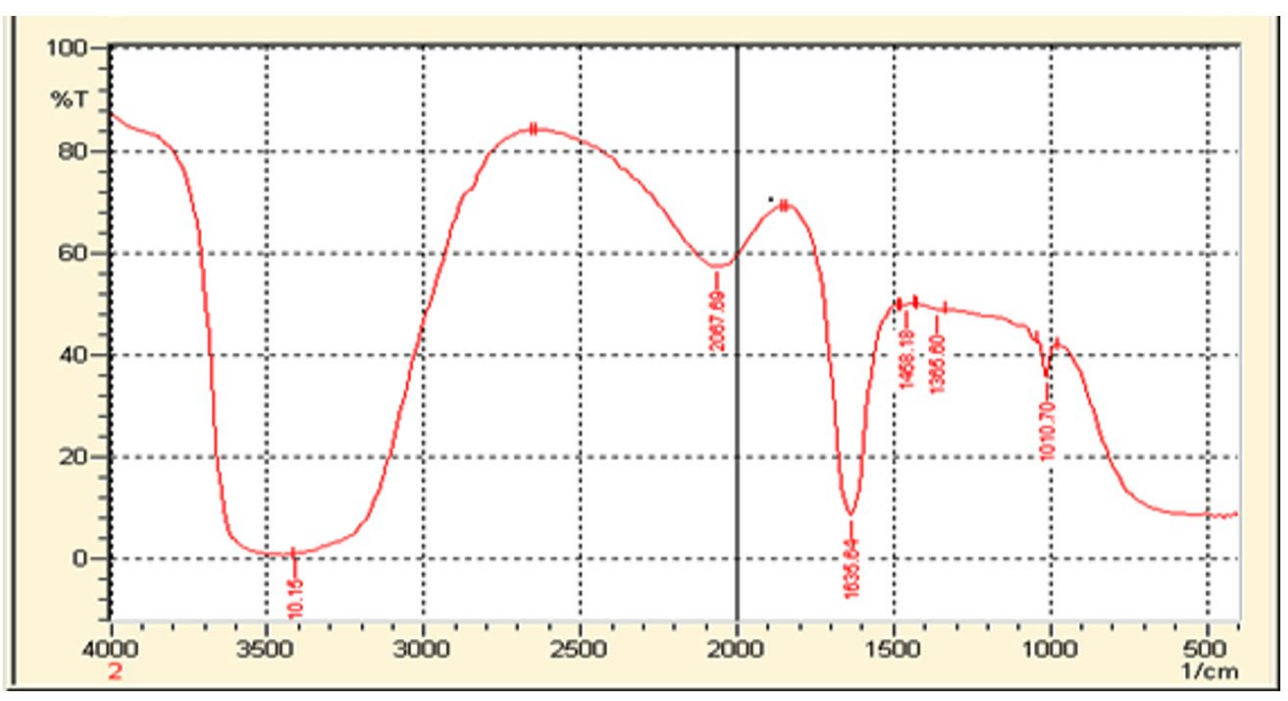

Fig. 2. FT-IR analysis of synthesized AuNPs from D. salicifolia crude extract. 


\section{RESULTS}

Results of phytochemical screening of D. salicifolia are given in Table 1. Our findings indicated the presence of tannins, saponins, flavonoids, steroids, terpenoids, coumarins, emodins, and soluble starch.

\section{Spectral analysis}

\section{UV-Visible spectrophotometer analysis}

Displayed in Fig. 1 is UV spectra of plant methanol crude extract, AuNPs, and AgNPs. Spectra showed no absorption bands in the range $395 \mathrm{~nm}$ to $750 \mathrm{~nm}$ for the methanol crude extracts. However, AuNPs exhibited an absorption band in the range 500 and $600 \mathrm{~nm}$, whereas AgNPs showed a band between 400 and 500 $\mathrm{nm}$. These observed surface plasmon resonance (SPR) absorption bands could be due to the free electrons of metallic nanoparticles. In the case of gold nanoparticles, the highest absorption was detected at a wavelength of $535 \mathrm{~nm}$, whereas that of silver was observed at $440 \mathrm{~nm}$.

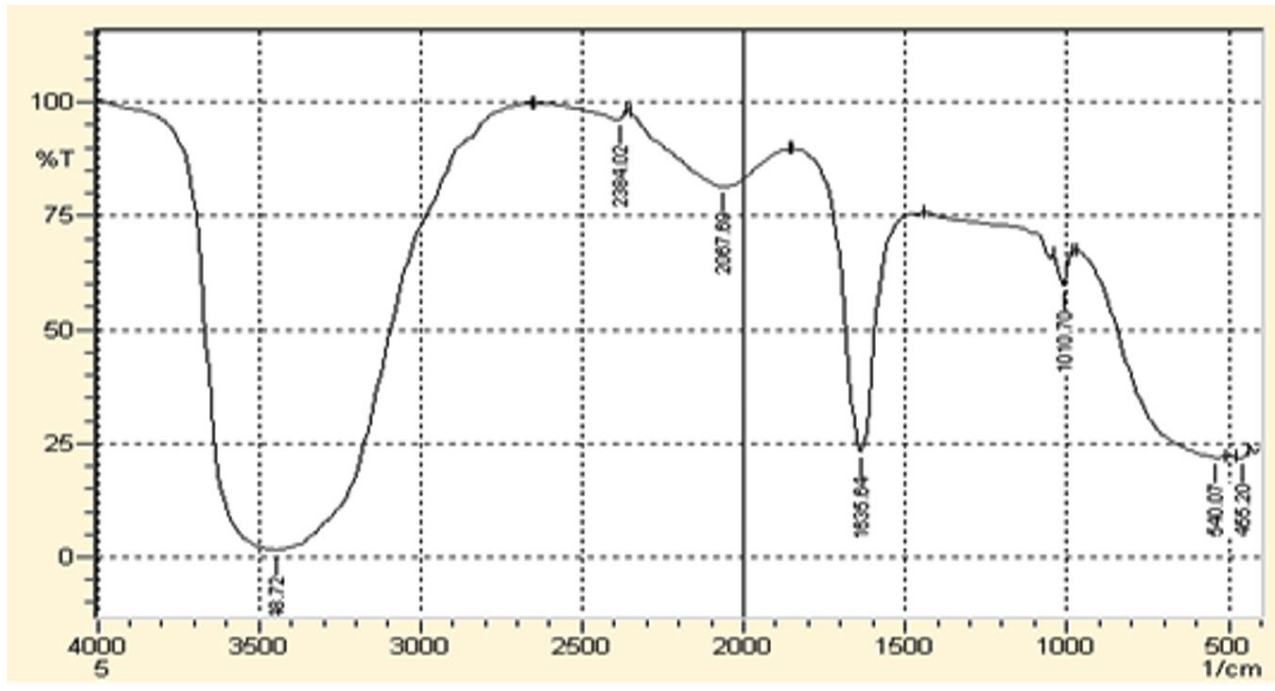

Fig. 3. FT-IR spectrum of synthesized AgNPs from D. salicifolia crude extract.

Table 1. Phytochemical analysis of crude extract and fractions of $D$. salicifolia

\begin{tabular}{lcccc}
\hline Chemical constituent & Crude extract & $\mathrm{n}$-Hexane & Chloroform & Ethyl acetate \\
\hline Alkaloids & - & - & - & - \\
Tannins & + & - & - & + \\
Anthraquinones & - & - & - & - \\
Glycosides & - & - & - & - \\
Reducing sugars & - & - & - & - \\
Saponins & + & + & + & - \\
Flavonoids & + & - & + & - \\
Phlobatanins & - & - & - & - \\
Steroids & + & + & + & + \\
Terpenoids & + & + & + & - \\
Cardiac glycosides & - & - & - & + \\
Coumarins & + & + & + & - \\
Emodines & + & - & - & + \\
Anthocyanin \& Betacyanins & - & - & - & - \\
Soluble starch & + & - & + & - \\
Fats/Fatty acids & - & - & - & \\
\hline
\end{tabular}

Keywords: (+): Presence, (-): Absence

Journal of Pure and Applied Microbiology 


\section{FT-IR analysis}

FTIR spectrum (Fig. 2 and 3 ) of D. salicifolia showed a number of absorption bands between $648 \mathrm{~cm}^{-1}$ and $3657 \mathrm{~cm}^{-1}$, assigned to various

Table 2. FTIR analysis of crude extract of D.salicifolia

\begin{tabular}{lccc}
\hline $\begin{array}{l}\text { Wave number } \\
\left(\mathrm{cm}^{-1}\right)\end{array}$ & $\begin{array}{c}\text { Functional } \\
\text { group }\end{array}$ & $\begin{array}{c}\text { Vibration } \\
{\left[\mathrm{cm}^{-1}\right]}\end{array}$ & Intensity \\
\hline 648.08 & $\mathrm{C}-\mathrm{H}$ & $\begin{array}{c}\text { Deform } \\
\text { stretch }\end{array}$ & $\begin{array}{l}68.642 \\
1026.13\end{array}$ \\
1211.30 & $\mathrm{R}-\mathrm{O}$ & stretch & 87.544 \\
1404.18 & $\mathrm{O}-\mathrm{H}$ & $\begin{array}{c}\text { deform } \\
\text { (in-plane) }\end{array}$ & 69.857 \\
1651 & & stretch & 85.398 \\
2839.22 & $\mathrm{C}=\mathrm{N}$ & stretch & 49.655 \\
2947.23 & $-\mathrm{CH}$ & stretch & 30.526 \\
3379.29 & $-\mathrm{CH},-\mathrm{CH} 2$ & stretch & 30.504 \\
3657.04 & $-\mathrm{NH}$ & stretch & 84.529 \\
\hline
\end{tabular}

functional groups of alkaloids, flavonoids, and other molecules as shown in Table 2. Considerable shifts were observed in the IR spectrum of AuNPs due to bio-reduction of $\mathrm{H}\left[\mathrm{AuCl}_{4}\right]$ in $D$. salicifolia extract. IR spectra $\left(\mathrm{cm}^{-1}\right)$ of extracts displayed bands at 3657, 3379, and 1211 assigned to $\mathrm{OH}$, $\mathrm{NH}$, and $\mathrm{C}=\mathrm{O}$ stretching, respectively, which are involved in the synthesis of AuNPs. Fig. 2 and 3 showed the FT-IR spectra of Au/AgNPs and D. salicifolia crude extract. Absorption bands at $3370 \mathrm{~cm}^{-1}$ are due to the stretching of aromatic and aliphatic $\mathrm{OH}$ groups, whereas peaks in the range $1400-1651 \mathrm{~cm}^{-1}$ are assigned to stretching of aromatic rings. On the other hand, the two peaks at 2839 and $2947 \mathrm{~cm}^{-1}$ are ascribed to the $=\mathrm{CH}$ group, and the band at $1211 \mathrm{~cm}^{-1}$ confirms the in-plane binding of $\mathrm{OH}$ group in the plant crude extract. In the FTIR spectra of Au/AgNPs, the peak for in-plane $\mathrm{OH}$ group bending is absent

Table 3. Antioxidant activity (\% DPPH. activity) of the crude extract, fractions and nanoparticles of $D$. salicifolia

\begin{tabular}{lccccccc}
\hline$\mu \mathrm{g} / \mathrm{mL}$ & Crude & $\mathrm{n}$-Hexane & $\mathrm{CHCl} 3$ & EtOAc & AuNPs & AgNPs & STD \\
\hline 10 & 60.59 & 45.49 & 48.68 & 59.98 & 62.59 & 59.98 & 91.59 \\
20 & 64.90 & 49.64 & 51.04 & 62.39 & 66.90 & 62.39 & 92.09 \\
40 & 72.27 & 55.51 & 57.07 & 69.54 & 73.27 & 68.54 & 92.59 \\
60 & 79.59 & 61.26 & 65.93 & 76.22 & 80.59 & 74.93 & 93.35 \\
80 & 83.90 & 66.14 & 70.49 & 81.59 & 86.90 & 78.14 & 94.47 \\
100 & 90.32 & 72.22 & 77.28 & 89.90 & 91.32 & 85.90 & 95.23 \\
\hline
\end{tabular}

$\mathrm{CHCl}^{3}$ : Chloroform, EtOAc: Ethyl acetate, AuNPs: Gold nanoparticles, AgNPs: Silver nanoparticles, STD: Standard (quercetin)

Table 4. Antibacterial activity of crude extract, fractions and nanoparticles of D.salicifolia

\begin{tabular}{lcccccccc}
\hline Microorganism & Gram & Crude & n-Hexane & CHCl3 & EtOAc & AuNPs & AgNPs & STD \\
\hline Klebsiella pneumonia & - & $10 \pm 0.45$ & $14 \pm 0.76$ & $12 \pm 0.65$ & $14 \pm 0.034$ & $12 \pm 0.23$ & $14 \pm 0.21$ & $30 \pm 0.01$ \\
Staphlococcus aureus & + & $12 \pm 0.39$ & $16 \pm 0.30$ & $14 \pm 0.21$ & $16 \pm 0.28$ & $12 \pm 0.21$ & $16 \pm 0.20$ & $30 \pm 0.02$ \\
Staphlococcus epidermidis & + & $12 \pm 0.44$ & $14 \pm 0.87$ & $14 \pm 0.19$ & 140.44 & $14 \pm 0.55$ & $12 \pm 0.12$ & $28 \pm 0.08$ \\
Bacillus sibtilis & + & $10 \pm 0.86$ & $14 \pm 0.23$ & $10 \pm 0.23$ & $14 \pm 0.23$ & $10 \pm 0.34$ & $14 \pm 0.21$ & $30 \pm 0.34$ \\
\hline
\end{tabular}

Well size: $6 \mathrm{~mm},(-/+)$ : Gram negative/ positive bacteria, AuNPs: Gold nanoparticles, AgNPs: Silver nanoparticles, STD: Standard (Streptomycin).

\begin{tabular}{lc}
\hline $\begin{array}{l}\text { Zone of } \\
\text { inhibition }(\mathrm{mm})\end{array}$ & Result \\
\hline $25-30$ & Excellent \\
$19-24$ & Good \\
$14-18$ & Moderate \\
$7-13$ & Poor \\
$0-6$ & Inactive \\
\hline
\end{tabular}

which shows the weakening of hydrogen bonding. A new peak at $1635 \mathrm{~cm}^{-1}$ can be attributed to the formation of quinones. The broadband in the range of $480-550 \mathrm{~cm}^{-1}$ confirms the presence of $\mathrm{Au} / \mathrm{AgNPs}$.

\section{AFM imagining}

AFM was employed to study the size and shape of Au/AgNPs. The size range of gold 
nanoparticles of $D$. salicifolia was from 5-100 $\mathrm{nm}$ as shown in Fig. 4, while the size of silver nanoparticles of $D$. salicifolia was in the range 5-100 nm (Fig. 5). In addition, the observed color change was due to the reaction and formation of Au/AgNPs (Fig. 6).

Biological activities

\section{Antioxidant activity}

Results of antioxidant activity of the methanol crude extract and nanoparticles of $D$. salicifolia are given in Table 3. Results revealed that
AuNPs were more active as free radical scavengers as compared to the methanol crude extracts.

\section{Antibacterial activity}

Results of antibacterial activity of crude methanol extract and of the synthesized nanoparticles are listed in Table 4. The result showed that the crude extract exhibited antibacterial activity against selected bacterial strains such as Staphylococcus aureus and Bacillus sibtilis with a zone of inhibition ranging from 10 to $16 \mathrm{~mm}$, whereas the AuNPs exhibited moderate activity with a zone inhibition range $10-14 \mathrm{~mm}$.

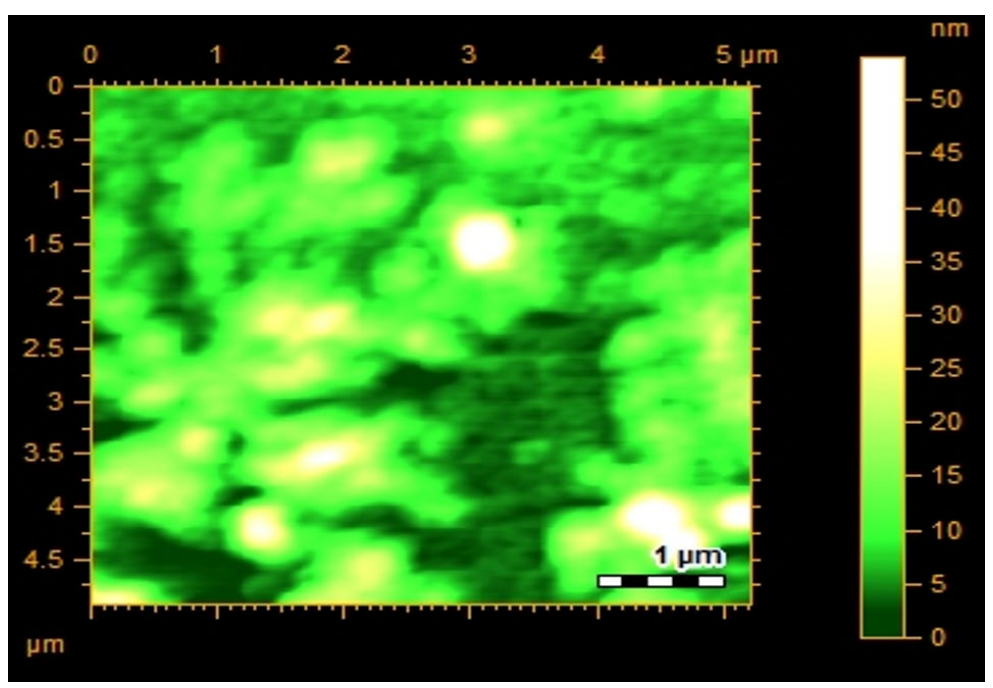

Fig. 4. AFM analysis of D. salicifolia gold nanoparticles.

Table 5. Antifungal activity of crude extract, different fractions and nanoparticles of $D$. salicifolia

\begin{tabular}{lccccccc}
\hline \multirow{2}{*}{ Microorganism } & \multicolumn{7}{c}{ Zone of inhibition (\%) } \\
& Crude & n-Hexane & $\mathrm{CHCl}_{3}$ & EtOAc & AuNPs & AgNPs & STD \\
\hline Aspergillus flavus & $50 \pm 0.76$ & $70 \pm 1.00$ & $80 \pm 1.01$ & $70 \pm 0.08$ & $70 \pm 0.16$ & $50 \pm 0.78$ & $100 \pm 0.07$ \\
Aspergillus niger & $60 \pm 0.87$ & $60 \pm 0.02$ & $70 \pm 0.00$ & $60 \pm 0.87$ & $60 \pm 0.56$ & $60 \pm 0.76$ & $100 \pm 0.08$ \\
Alternaria solani & $40 \pm 0.80$ & $60 \pm 0.34$ & $60 \pm 0.54$ & $60 \pm 0.87$ & $60 \pm 0.87$ & $50 \pm 0.44$ & $100 \pm 0.03$ \\
\hline
\end{tabular}

AuNPs: Gold nanoparticles, AgNPs: Silver nanoparticles, STD: Standard (Blank)

\begin{tabular}{lc}
\hline $\begin{array}{l}\text { Zone of } \\
\text { inhibition (\%) }\end{array}$ & Result \\
\hline $0-20$ & Excellent \\
$21-40$ & Good \\
$41-70$ & Moderate \\
$70-90$ & Poor \\
$91-100$ & Inactive
\end{tabular}

\section{Antifungal activity}

The antifungal activity of the methanol extract of $D$. salicifolia against Aspergillus niger, Aspergillus flavus, and Alternaria solani is presented in Table 5. Results showed a zone of inhibition ranging from 40 to $70 \mathrm{~mm}$, whereas those of AuNPs and AgNPs are from $50-70 \mathrm{~mm}$ against studied fungal strains. 


\section{DISCUSSION}

One of the objectives of this study was to evaluate the antioxidant activity of methanol crude extract from $D$. salicifolia, its various fractions, and Au/AgNPs. The crude methanol extract displayed excellent antioxidant effect at various concentrations. On the other hand, when $n$-hexane fraction was tested, it exhibited promising antioxidant effect. The chloroform fraction displayed a better antioxidant activity than $n$-hexane. This could be due to the differences in polarity between the solvents. Similarly, the ethyl acetate crude extract was more effective as a free radical scavenger than both $n$-hexane and chloroform. The ethyl acetate fractions was also found active. Normally the polar extract showed promising activity as compared to non-polar fractions, which is due to the polar compounds. All of these crude extracts exhibited substantial antioxidant activity. This significant antioxidant activity might be due to the chemical constituent of the plant which has various active compounds ${ }^{29,30}$. These findings are important since antioxidant activity is linked in many ways to protect from different diseases.

A standard protocol was followed for the antifungal effect of $D$. salicifolia against the Aspergillus flavus, Aspergillus niger, and Alternaria solani. Results revealed that the extract and various crude fractions inhibit the growth of fungi. Furthermore, the crude extract, various isolated fractions, and synthesized $\mathrm{Au} /$ AgNPs exhibited moderate activities. The low activity of crude extracts may due to the lack of antifungal compounds in theses extracts. However, chloroform extract, ethyl-acetate extract, and gold

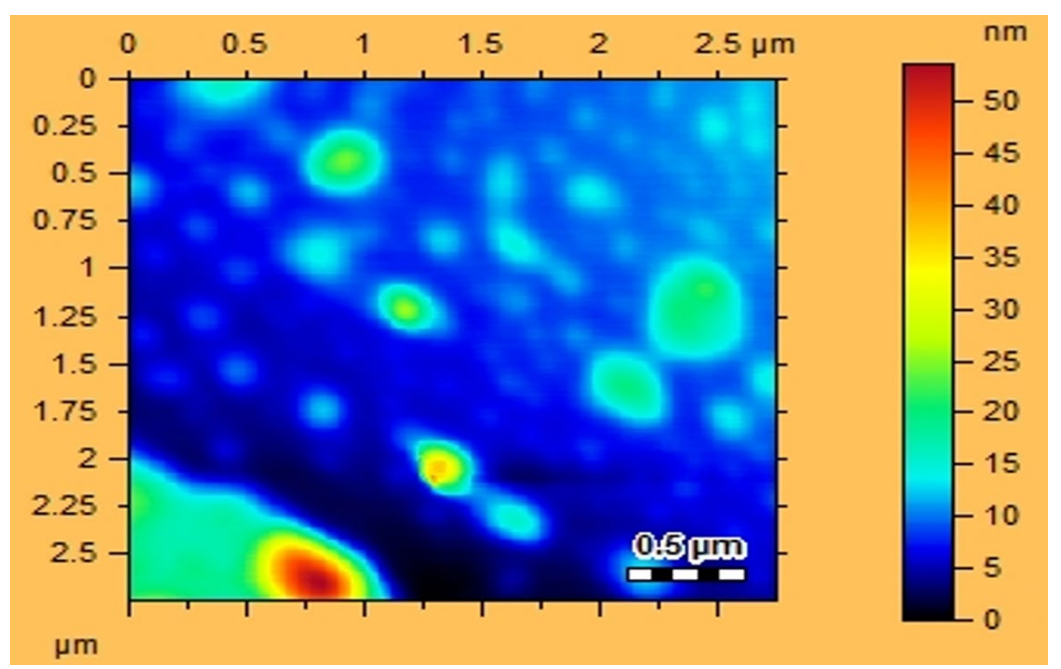

Fig. 5. AFM analysis of $D$. salicifolia silver nanoparticles.

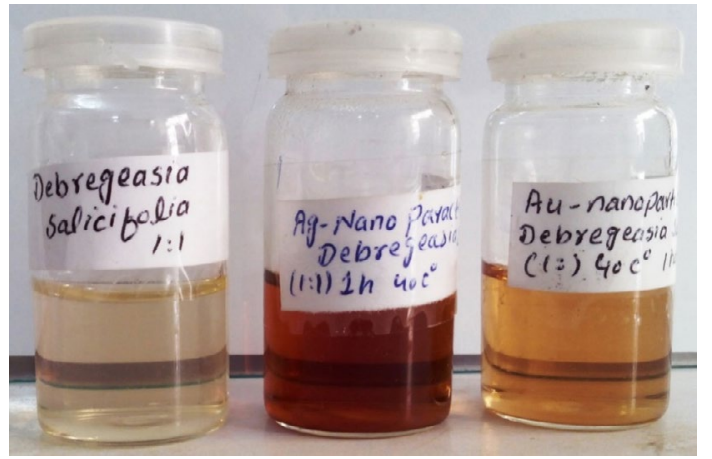

Fig. 6. Colour changes of $\mathrm{Ag} / \mathrm{AuNPs}$ from $D$. salicifolia. nanoparticle showed good activity as compared to other tested samples. All of the above-tested samples were also subjected to screening to assess their antibacterial activity. The result showed that tested samples exhibited moderate activity, wherein the ethyl acetate fraction and silver nanoparticles were more active compared to others with zone of inhibition range from 10-16 $\mathrm{mm}$.

Different characterization methods, such as UV, FT-IR and AFM, were utilized for confirmation and detection of the size of $\mathrm{Au} /$ 
AgNPs. In the UV spectra of plant crude extracts, and of AuNPs and AgNPs, no absorption bands were observed in the range from 395 to $750 \mathrm{~nm}$ in the spectra of crude extracts. However, AuNPs showed an absorption band in the range 500-600 $\mathrm{nm}$, whereas a band was observed in the range 400-500 nm in silver nanoparticles. Furthermore, the FT-IR spectrum of $D$. salicifolia crude extract showed an absorption band at $3370 \mathrm{~cm}^{-1}$ due to aromatic and aliphatic $\mathrm{OH}$ group stretching, and a band in the range $1400-1651 \mathrm{~cm}^{-1}$ attributed to aromatic rings ${ }^{29-30}$. The two absorption peaks in the range of $2839-2947$ and at $1211 \mathrm{~cm}^{-1}$ showed the presence of $=\mathrm{CH}$ and in-plane binding of $\mathrm{OH}$ group, respectively, in the plant crude extract. In the FTIR spectra of Au/AgNPs, the peak for in-plane bent $\mathrm{OH}$ group was absent and a new peak appeared at $1635 \mathrm{~cm}^{-1}$ due to the formation of quinones ${ }^{29-32}$. Additionally, the broadband in the range $480-550 \mathrm{~cm}^{-1}$ confirmed the presence of Au/AgNPs. According to AFM, the size of gold nanoparticles was from $15-50 \mathrm{~nm}$, and that of silver nanoparticles is in the range $20-40 \mathrm{~nm}$.

\section{CONCLUSIONS}

The phytochemical composition of D. salicifolia extract/fractions indicated the presence of tannins, saponins, flavonoids, steroids, terpenoids, coumarins, emodins, and soluble starch. In addition, findings from this investigation suggested that $D$. salicifolia can be used for the green synthesis of stable Au/AgNPs. These particles were prepared and characterised according to established procedures. The crude extracts of D. salicifolia and synthesized Au/AgNPs have exhibited promising antioxidant, antibacterial, and antifungal activitiesThe important bioactive compounds present in $D$. salicifolia may be used by pharmaceutical industries for new drug discovery. However, more detailed studies are required to establish the safety and efficacy of this plant.

\section{ACKNOWLEDGMENTS}

Authors are grateful to the higher education commission of Pakistan for financial support.

\section{CONFLICT OF INTEREST}

The authors declare that there is no conflict of interest.

\section{AUTHORS' CONTRIBUTION}

$\mathrm{SA}, \mathrm{AR}, \mathrm{KR}, \mathrm{GU}, \mathrm{FB}$ drafted the manuscript, compiled information from the literature, and designed the figures and tables. MM drafted the manuscript and gathered information from the literature. MFR reviewed and edited the manuscript.

\section{FUNDING}

Author (S. A. K.) is grateful to the Higher Education Commission of Pakistan for financial support under the indigenous $\mathrm{PhD}$ program under grant number 1270/SRGP/R\&D/HEC/2017.

\section{DATA AVAILABILITY}

All datasets generated or analysed during this study are included in the manuscript.

\section{ETHICS STATEMENT}

This article does not contain any studies with human participants or animals performed by any of the authors.

\section{REFERENCES}

1. Islam NU, Jalil K, Shahid M, Muhammad N, RaufA. Pistacia integerrima gall extract mediated green synthesis of gold nanoparticles and their biological activities. Arabian Journal of Chemistry. 2015;12(8):2310-2319. doi: 10.1016/j.arabjc.2015.02.014

2. Rizwan M, Amin S, Malikovna BK, et al. Green synthesis and antimicrobial potential of silver nanoparticles with Boerhavia procumbens extract. J Pure Appl Microbiol. 2020;14(2):1437-1451. doi: 10.22207/JPAM.14.2.42

3. Dykman LA, Khlebtsov NG. Gold nanoparticles in biology and medicine: recent advances and prospects. Acta Nature. 2011;3(2):34-55. doi: 10.32607/20758251-2011-3-2-34-55

4. Solano-Umana V, Vega-Baudrit JR. Gold and silver nanotechnology on Medicine. J Chem Biochem. 2015;3(1):21-33.

5. The Wealth of India: A dictionary of Indian raw materials and industrial products. Raw Materials. D-E. Published by Council of Scientific and Industrial Research New Delhi. 1952;III:23.

6. Ali, Nasir E. Flora of Pakistan, Fakhri Printing Press, Karachi. 1972:195.

7. Akbar EM, Riaz M, Malik A. Ursene type nortriterpene from Debregeasia salicifolia. Fitoterapia. 2001;72(4):382-385. doi: 10.1016/S0367326X(00)00338-5

8. Akbar E, Malik A. Antimicrobial triterpenes from Debregeasia salicifolia. Nat Prod Lett. 2002;16(5):339344. doi: 10.1080/10575630290033088

9. Bibi Y, Nisa S, Chaudhary FM, Zia M. Antibacterial activity of some selected medicinal plants of Pakistan. BMC Complement Altern Med. 2011;11(1):47-52. doi: 


\subsection{6/1472-6882-11-52}

10. Alam MN, Bristi NJ, Rafiquzzaman M. Review on in vivo and in vitro methods evaluation of antioxidant activity. Saudi Pharm J. 2013;21(2):143-152. doi: 10.1016/j. jsps.2012.05.002

11. Herz W, Santhanam PS, Wahlberg I. 3-epibetulinic acid, a new triterpenoid from Picramnia pentandra. Phytochem. 1972;11(10):3061-3063. doi: 10.1016/0031-9422(72)80106-7

12. Hai-X K, Kasai R, Zhong SL. Edible Medicinal and NonMedicinal Plants. Chem Pharm Bull. 1989;51(8):22322236.

13. Uddin G, Rauf A, Siddiqui BS, Shah SQ. Preliminary comparative phytochemical screening of Diospyros lotus Stewart. Middle-East J Sci Res. 2011;10 (1):78-81.

14. Uddin G, Rauf A, Akhtar S. Studies on chemical constituents, phytochemical profile and pharmacological action Datura alba. Middle-East J Med Plants Res. 2012;1(1):14-18.

15. Rauf A, Qaisar M, Uddin G, Akhtar S, Muhammad N, Qaisar M. Preliminary phytochemical screening and antioxidant profile of Euphorbia prostrate. Middle-East J Med Plant Res. 2012;1(1):9-13.

16. Uddin G, Rauf A. Phytochemical screening, antimicrobial and antioxidant activities of aerial parts of Quercus robur. L. Middle-East J Med Plant Res. 2012;1(1):01-04.

17. Uddin G, Rauf A, Arfan M, Ali M, Qaisar M, Saadiq M, Atif M. Preliminary phytochemical screening and antioxidant activity of Bergenia caliata. Middle-East J Sci Res. 2012;11(8):1140-1142.

18. Uddin G, Rauf A. Phytochemical screening and biological activity of the aerial parts of Elaeagnus umbellata. Scientific Research and Essays. 2012;7(43): 3690-3694.

19. Uddin G, Gul S, Rauf A. Preliminary phytochemical screening, in vitro antimicrobial and antioxidant evaluation of Withania somnifera Dunal. World Appl Sci J. 2013;27:562-565.

20. Yasmin A, Ramesh K, Rajeshkumar SJ. Optimization and stabilization of gold nanoparticles by using herbal plant extract with microwave heating, Nano. Convergence. 2014;1:6-12. doi: 10.1186/s40580-014-0012-8

21. Alkilany AM, Lohse SE, Murphy CJ. The gold standard: gold nanoparticle libraries to understand the nano-bio interface. Acc Chem Res. 2012;46(3):650-661. doi: 10.1021/ar300015b

22. Majumdar R, Bag G, Maity N. Acacia nilotica (Babool) leaf extract mediated size-controlled rapid synthesis of gold nanoparticles and study of its catalytic activity.
Inter Nano Lett. 2013;3(1):47-53. doi: 10.1186/22285326-3-53

23. Duan XJ, Zhang WW, Li XM, Wang BG. Evaluation of antioxidant property of extract and fractions obtained from a red alga, Polysiphonia urceolata. Food Chem. 2006;95(1):37-43. doi: 10.1016/j. foodchem.2004.12.015

24. Blois MS. Antioxidant determinations by the use of a stable free radical. Nature. 1958;181(4617):11991200. doi: 10.1038/1811199a0

25. Rauf A, Khan A, Rasool S, Shah ZA, Saleem M. In vitro antifungal activity of three selected Pakistani medicinal plants. Middle-East J Med Plant Res. 2012;1(2):41-43.

26. Rizwan $M$, Hussain $M$, Muhammad $M$, et al. Green synthesis and antimicrobial evaluation of silver nanoparticles mediated by leaf extract of Syzygium cumini against poultry pathogens. Micro \& Nano Letters. 2020;15(9):600-605. doi: 10.1049/mnl.2019.0617

27. Zaman K, Bakht J, Malikovna BK, et al. Trillium govanianum Wall. Ex. Royle rhizomes extract medicated Silver nanoparticles and their anti-microbial activity. Green Processing and Synth. 2020;9:503-514. doi: 10.1515/gps-2020-0054

28. Begum, G., Dastagir, G., Rauf, A. et al. Pharmacognostic characteristics and phytochemical profile of various parts of Parthenium hysterophorus. Rend. Fis. Acc. Lincei 31, 853-872 (2020). doi: 10.1007/s12210-02000911-z

29. Nisar M, Khan SA, Gul M, Rauf A, Zafar S, Ramadan MF. Synthesis, Characterization, and Antimicrobial Properties of Sparfloxacin-Mediated Noble Metal Nanoparticles. J Pure Appl Microbiol. 2020;14(3):17891800. doi: 10.22207/JPAM.14.3.17

30. Islam NU, Jalil K, Shahid M, Muhammad N, Rauf A. Pistacia integerrima gall extract mediated green synthesis of gold nanoparticles and their biological activities. Arab J Chem. 2019;12(8):2310-2319. doi: 10.1016/j.arabjc.2015.02.014

31. Islam NU, Jalil K, Shahid M, et al. Green synthesis and biological activities of gold nanoparticles functionalized with Willow Salix Alba. Arab J Chem. 2019;12(8):29142925. doi: 10.1016/j.arabjc.2015.06.025

32. Sultana K, Ahmad B, Rauf A, Huang L, Ramadan MF. Synthesis, characterization and pharmacological activities of silver nanoparticles using Bistorta affinis and Malcolmia cabulica extracts. Bioinspired, Biomimetic and Nanobiomaterials. 2020;9(1):7-15. doi: 10.1680/jbibn.18.00012 